\title{
Hidden Diversity of Crown Rust Resistance within Genebank Resources of Avena sterilis L.
}

\author{
Edyta Paczos-Grzęda ${ }^{1}$ (D) Maja Boczkowska ${ }^{2} \mathbb{D}$, Sylwia Sowa ${ }^{1, * \mathbb{D}}$, Aneta Koroluk ${ }^{1}$ (D) and Joanna Toporowska ${ }^{1} \mathbb{D}$ \\ 1 Institute of Plant Genetics, Breeding and Biotechnology, University of Life Sciences in Lublin, 20-950 Lublin, \\ Poland; edyta.paczos@up.lublin.pl (E.P.-G.); aneta.koroluk@up.lublin.pl (A.K.); \\ joanna.toporowska@up.lublin.pl (J.T.) \\ 2 National Centre for Plant Genetic Resources, Plant Breeding and Acclimatization Institute—NRI, Radzików, \\ 05-870 Błonie, Poland; m.boczkowska@ihar.edu.pl \\ * Correspondence: sylwia.sowa@up.lublin.pl
}

Citation: Paczos-Grzęda, E.;

Boczkowska, M.; Sowa, S.; Koroluk,

A.; Toporowska, J. Hidden Diversity

of Crown Rust Resistance within

Genebank Resources of Avena sterilis

L.. Agronomy 2021, 11, 315.

https://doi.org/10.3390/

agronomy11020315

Academic Editors: Caterina Morcia and Valentina Manstretta

Received: 30 December 2020

Accepted: 5 February 2021

Published: 10 February 2021

Publisher's Note: MDPI stays neutral with regard to jurisdictional claims in published maps and institutional affiliations.

Copyright: (c) 2021 by the authors. Licensee MDPI, Basel, Switzerland This article is an open access article distributed under the terms and conditions of the Creative Commons Attribution (CC BY) license (https:// creativecommons.org/licenses/by/ $4.0 /)$
Abstract: The most widespread and damaging fungal disease of the oat plant is crown rust. Resistance to the crown rust pathogen, Puccinia coronata Cda. f. sp. avenae (Pca), at the seedling stage of Avena sterilis accessions from the Polish national genebank was characterised by five North American and Polish pathotypes of $\mathrm{Pca}$ of diverse pathogenicity. Pca pathogenicity was determined on a series of 34 differential lines carrying known seedling resistance genes. Seventy-five percent of studied accessions showed a heterogeneous infection pattern, $17 \%$ behaved as homogenous susceptibles, and $7 \%$ of tested genotypes could be unambiguously described as resistant. This study proved that A. sterilis accessions preserved in a genebank as complex populations could be a very valuable source of resistance to crown rust. The complexity of analysed populations was ascertained by a detailed variance analysis of transformed resistance/susceptibility data. We demonstrate here that hidden sources of resistance may be discovered in accessions with general susceptibility.

Keywords: accessions heterogeneity; complex populations; Puccinia coronata f.sp. avenae; resistance diversity

\section{Introduction}

Puccinia coronata f. sp. avenae, which causes crown rust in oats, exhibits a high level of pathogenic variation and dynamic shifts in virulence as a consequence of both sexual and asexual reproduction [1-5]. The fungus displays a huge number of pathogenic variants and efficient adaptability [6]. Crown rust is considered the most harmful disease of the oat plant, and resistance conditioned by race-specific $\left(P_{c}\right)$ genes has been the primary means of control [7]. Over $100 P_{C}$ genes have been discovered in different species belonging to the Avena genus [3,8], but the diversity of the pathogen rapidly leads to loss of effectiveness in resistance conferred by single dominant genes with different specificities towards $P c a$ isolates, so that new resistance sources are needed urgently. Because of the large number of resistance genes identified in different wild species [7,9], it seems unlikely that these resources have been exhausted. Nazareno et al. [10] proposed that systematic evaluations of germplasm collections could uncover new genes and improve options for crown rust management.

The Avena collections maintained in gene banks worldwide consist of 131,000 accessions, stored by 125 holders in 63 countries, and are the eighth most numerous collections of crop germplasm after wheat, rice, barley, maize, beans, sorghum, and soybeans [11]. Twenty-four percent of Avena global resources are identified as wild species, of which the most plentiful is the hexaploid Avena sterilis L., with more than 23,000 accessions. Ninetytwo percent of these are stored in Canada, the United States, and Israel. Moreover, 66\% of A. sterilis accessions originate from Israel, a relatively small representative of the species geographical range. A. sterilis genotypes collected from Israel and other Mediterranean 
countries were the sources of forty-four crown rust resistance genes [7,12-15]. Some of these genes were introduced into North American, European, and Australian oat cultivars. Accessions originating from Israel provided $P c 39, P c 48, P c 58, P c 59, P c 60$, and $P c 61$; accessions from Algeria provided Pc38 and Pc68; and the Pc50 gene donor was from Tunisia [7,12-14].

Polish germplasm resources of genus Avena are the ninth most numerous collection worldwide overall, with the $A$. sterilis collection ranking seventh [11]. The studies presented here use a detached leaf method to screen individual seedling resistance to crown rust in accessions from this collection [16]. Our survey proved that $A$. sterilis accessions collected in Morocco and preserved in a genebank as a complex population could be a very valuable source of resistance to crown rust. In the present paper, as a continuation of previous efforts, the complexity of analysed populations has been characterized and precisely assessed by detailed variance analysis of transformed resistance/susceptibility data. The level of the internal variation of Avena species has never been analysed using the approach applied in our studies.

\section{Materials and Methods}

The research was carried out on 41 accessions of the A. sterilis (Table 1). The seeds were obtained from the National Centre for Plant Genetic Resources in Radzików, Poland. The accessions were acquired during field expeditions in Morocco (18 accessions), Ukraine (5 accessions), and Iran (2 accessions) from 1986 to 2006. The origin of 15 accessions could not be identified.

Table 1. Accession list containing basic information and statistical data.

\begin{tabular}{|c|c|c|c|c|c|c|}
\hline No. & Genebank Number & Acquisition Date & Country of Origin & uHe & $\mathbf{I}$ & $\begin{array}{c}\text { Post Hoc Group } \\
\text { Comparison }\end{array}$ \\
\hline 1 & PL 50280 & 1983 & $n a$ & 0.087 & 0.061 & ABCDEFGHIJ \\
\hline 2 & PL 51557 & 1985 & MAR & 0.163 & 0.114 & GHIJ \\
\hline 3 & PL 51559 & 1985 & MAR & 0.162 & 0.110 & GHIJ \\
\hline 4 & PL 51565 & 1985 & MAR & 0.022 & 0.015 & A \\
\hline 5 & PL 51589 & na & MAR & 0.084 & 0.059 & ABCDEFGH \\
\hline 6 & PL 51818 & 1993 & MAR & 0.157 & 0.107 & FGHIJ \\
\hline 7 & PL 51823 & 1993 & MAR & 0.038 & 0.025 & $\mathrm{ABC}$ \\
\hline 8 & PL 51832 & 1993 & MAR & 0.127 & 0.087 & CDEFGHIJ \\
\hline 9 & PL 51836 & 1993 & MAR & 0.060 & 0.043 & $\mathrm{ABCDE}$ \\
\hline 10 & PL 51837 & 1993 & MAR & 0.096 & 0.066 & ABCDEFGHIJ \\
\hline 11 & PL 51838 & 1993 & MAR & 0.119 & 0.083 & BCDEFGHIJ \\
\hline 12 & PL 51839 & 1993 & MAR & 0.138 & 0.090 & DEFGHIJ \\
\hline 13 & PL 51840 & 1993 & MAR & 0.097 & 0.066 & ABCDEFGHIJ \\
\hline 14 & PL 51841 & 1993 & MAR & 0.180 & 0.116 & $\mathrm{~J}$ \\
\hline 15 & PL 51851 & 1993 & MAR & 0.170 & 0.118 & HIJ \\
\hline 16 & PL 51856 & 1993 & MAR & 0.147 & 0.098 & EFGHIJ \\
\hline 17 & PL 51857 & 1993 & MAR & 0.050 & 0.035 & $\mathrm{ABCD}$ \\
\hline 18 & PL 51860 & 1993 & MAR & 0.146 & 0.098 & EFGHIJ \\
\hline 19 & PL 52105 & 1995 & na & 0.122 & 0.084 & BCDEFGHIJ \\
\hline 20 & PL 52106 & 1995 & na & 0.078 & 0.052 & ABCDEFGH \\
\hline 21 & PL 52108 & 1995 & $n a$ & 0.085 & 0.060 & ABCDEFGHI \\
\hline 22 & PL 52109 & 1995 & na & 0.098 & 0.067 & ABCDEFGHIJ \\
\hline 23 & PL 52110 & 1995 & MAR & 0.071 & 0.046 & ABCDEFG \\
\hline 24 & PL 52111 & 1995 & na & 0.178 & 0.116 & IJ \\
\hline 25 & PL 52205 & 1997 & na & 0.061 & 0.042 & $\mathrm{ABCDE}$ \\
\hline 26 & PL 52209 & 1997 & na & 0.060 & 0.043 & ABCDE \\
\hline 27 & PL 52212 & 1997 & na & 0.107 & 0.070 & ABCDEFGHIJ \\
\hline 28 & PL 52217 & 1997 & na & 0.102 & 0.068 & ABCDEFGHIJ \\
\hline 29 & PL 52278 & 2000 & na & 0.100 & 0.070 & ABCDEFGHIJ \\
\hline 30 & PL 52353 & 2001 & UKR & 0.136 & 0.094 & DEFGHIJ \\
\hline
\end{tabular}


Table 1. Cont.

\begin{tabular}{|c|c|c|c|c|c|c|}
\hline No. & Genebank Number & Acquisition Date & Country of Origin & uHe & I & $\begin{array}{c}\text { Post Hoc Group } \\
\text { Comparison }\end{array}$ \\
\hline 31 & PL 52355 & 2001 & UKR & 0.045 & 0.030 & ABCD \\
\hline 32 & PL 52363 & 2001 & UKR & 0.088 & 0.062 & ABCDEFGHIJ \\
\hline 33 & PL 52435 & 2004 & UKR & 0.065 & 0.047 & ABCDEF \\
\hline 34 & PL 52442 & na & na & 0.155 & 0.105 & FGHIJ \\
\hline 35 & PL 52459 & 2006 & na & 0.091 & 0.064 & ABCDEFGHIJ \\
\hline 36 & PL 52460 & 2006 & $n a$ & 0.098 & 0.065 & ABCDEFGHIJ \\
\hline 37 & PL 52461 & 2006 & $n a$ & 0.068 & 0.047 & $\mathrm{ABCDEF}$ \\
\hline 38 & PL 52462 & 2006 & $n a$ & 0.031 & 0.022 & $\mathrm{AB}$ \\
\hline 39 & PL 501552 & 2004 & IRN & 0.064 & 0.044 & ABCDEF \\
\hline 40 & PL 502692 & 2005 & UKR & 0.052 & 0.035 & $\mathrm{ABCD}$ \\
\hline 41 & PL 502695 & 2004 & IRN & 0.105 & 0.071 & ABCDEFGHIJ \\
\hline
\end{tabular}

$\mathrm{I}=$ Shannon index, $\mathrm{uHe}=$ Nei coefficient, $\mathrm{IRN}=\mathrm{Iran}, \mathrm{MAR}=$ Morroco, $\mathrm{UKR}=$ Ukraine, $n a=$ not available

Crown rust resistance of each of the accessions was assessed using five highly virulent P. coronata isolates (Pca). CR230, CR241, and CR257 were kindly supplied by Dr. J. Menzies from the Morden Research and Development Centre, AAFC, Canada, whereas 94(63) and 51(22) were selected from a wide collection of single-pustule pathotypes that originated from Polish fungus populations. The virulence of each isolate used in the study was previously characterized on the basis of the susceptibility/resistance reaction of 34 differential oat lines with single gene resistance (Table 2).

Table 2. Virulence profile of Puccinia coronata f.sp. avenae isolates used for testing resistance of Avena sterilis accessions.

\begin{tabular}{|c|c|c|}
\hline Isolate Number & Phenotype Code ${ }^{1}$ & Virulence to Differentials \\
\hline $51(22)$ & SBLP & $\begin{array}{c}\text { Pc14, Pc35, Pc40, Pc45, Pc46, Pc51, Pc54, Pc57,Pc62, Pc6, Pc96, } \\
\text { Pc97, Pc98, Pc101, Pc104 }\end{array}$ \\
\hline $94(63)$ & NJBP & $\begin{array}{c}\text { Pc36, Pc39, Pc40, Pc46, Pc48, Pc54, Pc55, Pc57, Pc61, Pc62, Pc64, } \\
\text { Pc70, Pc71, Pc94, Pc96, Pc97, Pc98, Pc103-1 }\end{array}$ \\
\hline CR230 & LQCB & $\begin{array}{c}\text { Pc14, Pc35, Pc36, Pc38, Pc39, Pc40, Pc55, Pc57, Pc59, Pc60, Pc61, } \\
\text { Pc63, Pc70, Pc71, Pc91 }\end{array}$ \\
\hline CR241 & DSGB & $\begin{array}{c}\text { Pc14, Pc36, Pc38, Pc39, Pc46, Pc48, Pc52,Pc55, Pc61, Pc63, Pc70, } \\
\text { Pc71, Pc103-1 }\end{array}$ \\
\hline CR257 & BRBG & Pc36, Pc38, Pc39, Pc55, Pc56, Pc61, Pc63, Pc68, Pc70, Pc71, Pc94 \\
\hline
\end{tabular}

${ }^{1}$ Phenotype code based on the standard differentials set.

The host/pathogen test [17] according to Sowa et al. [18] was applied. To screen the resistance of the $A$. sterilis accessions, ten leaf fragments were used, each from a different seedling. Leaves were placed into Petri dishes or 12-well culture plates filled with agar $(0.6 \%)$ and benzimidazole $(3.4 \mathrm{mM})$ medium according to the methodology of Hsam et al. [17]. Inoculations were performed in a settling tower by applying 500-700 spores of $P$. coronata per square centimetre. The plates were incubated for 10 days in a phytotron at about $18{ }^{\circ} \mathrm{C}$ with $70 \%$ humidity and light intensity of approximately $4 \mathrm{kLx}$. Crown rust disease symptoms were evaluated 10 days after inoculation using the $0-4$ infection type (IT) qualitative scale $[10,19]$, which were transformed to S, MS, MR, R, and $H R$, where $S=4$ = susceptible, large to moderately large pustules with little or no chlorosis; $\mathrm{MS}=3$ = moderately susceptible, moderately large pustules surrounded by extensive chlorosis; $\mathrm{MR}=2,2 \mathrm{~N}, 12 \mathrm{C}, ; \mathrm{C}=$ moderately resistant, small pustule surrounded by chlorosis or necrosis; $\mathrm{R}=;-\mathrm{N}, ; \mathrm{C}, ;+\mathrm{C}, ; \mathrm{N}=$ resistant, chlorotic or necrotic flecking; and $0=\mathrm{HR}=$ highly resistant, no visible reaction $[10,16,18-20]$. 
The raw data were transformed into a binary matrix. In order to ensure that the matrix reflects the accuracy of the initial results in the best possible way, each plant resistance response level to a particular pathotype of $P c a$ (assessed in 0-4 IT scale) was treated as a single variable. The presence of each resistance response level was encoded as 1, while its absence was encoded as 0. The diversity parameters such as Shannon's [21] and Nei's [22] diversity indices were calculated, and the results were subjected to one-way analysis of variance (one-way ANOVA) with Tukey's test for post hoc comparison. In order to compare individuals and their relationships, the dissimilarity matrix was built using a Dice coefficient [23] according to the following formula:

$$
D=1-\frac{2 x_{i j}}{2 x_{i j}+x_{i}+x_{j}}
$$

where $x_{i j}$ is the number of variables present both in $i$-th and $j$-th individuals, $x_{i}$ is the number of variables unique for the $i$-th individual, and $x_{j}$ is the number of variables unique for the $j$-th individual. Intra-accession differences were calculated according to Nei's unbiased distance formula:

$$
\begin{gathered}
u D=-\ln (I) \\
I=\frac{J_{x y}}{\sqrt{J_{x} J_{y}}} \\
J_{x y}=\sum_{i=1}^{k} p_{i x}^{2} p_{i y}^{2} \\
J_{x}=\sum_{i=1}^{k} p_{i x}^{2} \\
J_{y}=\sum_{i=1}^{k} p_{i y}^{2}
\end{gathered}
$$

where $p_{i x}$ and $p_{i y}$ are the frequency of $i$-th variable in accessions $x$ and $y$ [24]. For hierarchical clustering, dissimilarity matrices were used to construct dendrograms using Ward's method. Principal coordinate analysis (PCoA) was performed to visualize the relationships between individuals and accessions. Analysis of molecular variance (AMOVA) was used to partition the diversity [25]. The variance components were tested statistically using 9999 permutations. The binary data were also analysed for population structure using a model-based Bayesian clustering. The models were computed for $\mathrm{K}=1 \div 10$ (K-number of subpopulation). Each model was tested five times with 10,000 burn-in cycles and 100,000 iterations. The results were tested to find the best model with the highest $\Delta \mathrm{K}$ value. All of the above-mentioned analyses were performed using GenAlEx 6.5 [26], R environment for statistical computing, STRUCTURE v2.3.4 [27], and CLUMPAK [28] software.

\section{Results}

Resistance reactions of $41 \mathrm{~A}$. sterilis accessions to $P$. coronata isolates in the host/pathogen tests ranged from susceptible (S) to highly resistant (HR). Thirty-one (76\%) of the tested A. sterilis accessions displayed heterogeneous phenotypes, and the specific Pca inoculation response of single seedlings within accessions could vary from highly resistant to susceptible. Only seven accessions (17\%) were completely susceptible on all tested races of $P$. coronata. The remaining three accessions (7\%) displayed a consistently resistant phenotype. Two of these accessions were immune to races 51(22) and 94(63) (PL 51589, PL 52110), and the last one (PL 51836) was assessed as resistant or highly resistant to all Pca strains.

Variation within the accessions was determined on the basis of the level of resistance reaction of each plant inoculated with five isolates of $P$. coronata. The average values of both calculated coefficients were relatively low and were, respectively, 0.101 for the Shannon index (I) and 0.069 for the Nei coefficient ( $\mathrm{uHe}$ ). In the group with the lowest variation 
we found both accessions, wherein all individuals were characterized by complete lack of resistance to all tested isolates (PL 51565, PL 51823, PL 51857), as well as accessions wherein all individuals were highly resistant to all Pca isolates (PL 51836) (Table 1). Low variability was also noted for accessions that did not show full resistance to all tested Pca isolates, but wherein all individuals displayed the same resistance level and pattern. The greatest diversity was observed in accessions PL 51841, PL 52111, and PL 51851. These were mixtures of individuals with different levels of resistance to all Pca isolates, which displayed the highest level of heterogeneity. The analysis of variance (ANOVA) revealed a statistically significant difference between the examined accessions with respect to the Shannon index $(p=0.01)$. Homogeneous groups were identified by a post hoc Tukey's test, and the results are given in Table 1. The analysis of molecular variance (AMOVA) showed that the distribution of variability among individuals and among accessions was comparable $\left(\phi_{\mathrm{PT}}=0.515\right)$.

Due to the specificity of the data, the coefficient of dissimilarity of individuals reached its maximum range, i.e., 0-1. The distance among accessions ranged from 0.003 (PL 51837-PL 52109 and PL 51838-PL 52459) to 0.251 (PL 51565-PL 52462). Hierarchical clustering and principal coordinate analysis ( $\mathrm{PCoA}$ ) were performed on the basis of both dissimilarity matrices.

A dendrogram based on accession dissimilarity identified four main clusters, composed of 9, 11, 14, and 7 accessions, respectively (Figure 1). The second group consisted mainly of the Moroccan accessions, which were generally characterized by the highest level of resistance. The fourth cluster encompassed seven accessions originating mainly from Ukraine and Iran. They were characterized by susceptibility to all tested Pca isolates.

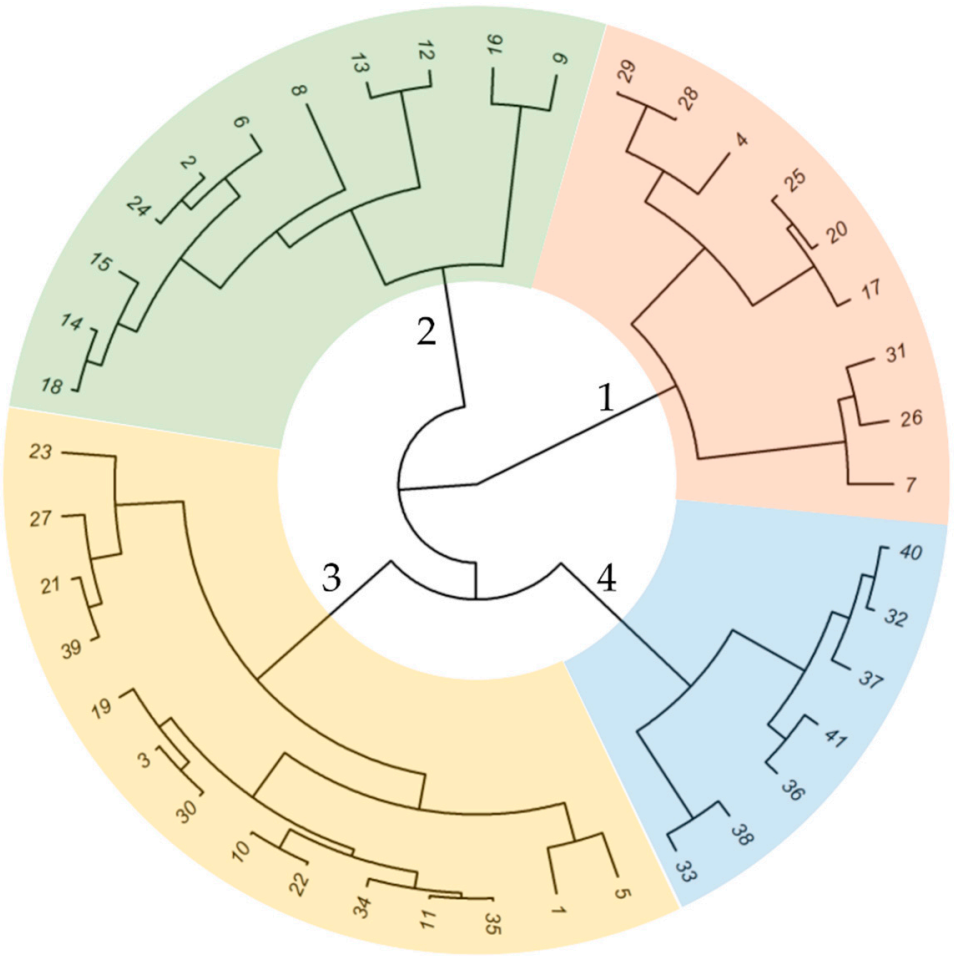

Figure 1. The Ward's clustering dendrogram of 41 accessions of Avena sterilis L. based on Nei's unbiased distance matrix [24]. The accessions were labelled with numbers in accordance with Table 1. Four main clusters were surrounded by contours and filled in.

A dendrogram based on individuals' data also showed the presence of four main clusters composed of 124, 109, 25, and 152 individuals, respectively (Figure S1). As a result of internal differentiation of accessions, individuals from the same source could be placed in different groups. The smallest and most interesting cluster, cluster 3, was composed of 25 individuals belonging to five accessions: PL 51836 (10 individuals), PL 51856 (9 individuals), 
PL 51851 (4 individuals), and PL 51841 and PL 52111 (1 individual each). Most of them displayed the highest level of resistance. The remaining clusters were composed of a mixture of less resistant or totally susceptible individuals. They were grouped according to the resistance level and pattern in the subordinate units.

The first three axes of PCoA of individuals explained $33.12 \%$ of the total variance $(12.63 \%, 10.62 \%$, and $9.87 \%$ respectively) (Figures $2 \mathrm{a}$ and $3 \mathrm{a})$. The plot of the first two PCoAs presented large variation; however, a clear identification of any grouping pattern was difficult (Figures $2 b$ and $3 b$ ). Clearly, the individuals from the accessions gathered in Morocco covered all the detected variability, which was also reflected in the results of the coefficients of variation (Figure 4). The plot in Figure $3 \mathrm{~b}$ also clearly indicated that four to five isolate-resistant individuals were concentrated in quarter IV. All of them were of Moroccan origin (Figure $2 \mathrm{~b}$ ). Analysis of resistance to individual Pca isolates presented in Figure $5 b, d, f, h, j$ showed that individuals resistant to a particular isolate were present in different parts of the plot, which indicated that there were many potential sources of resistance.

(a)

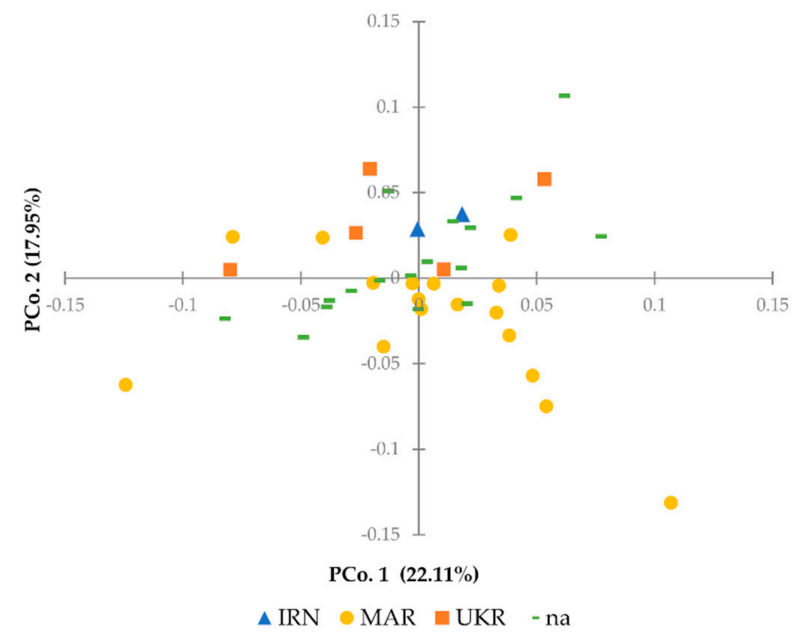

(b)

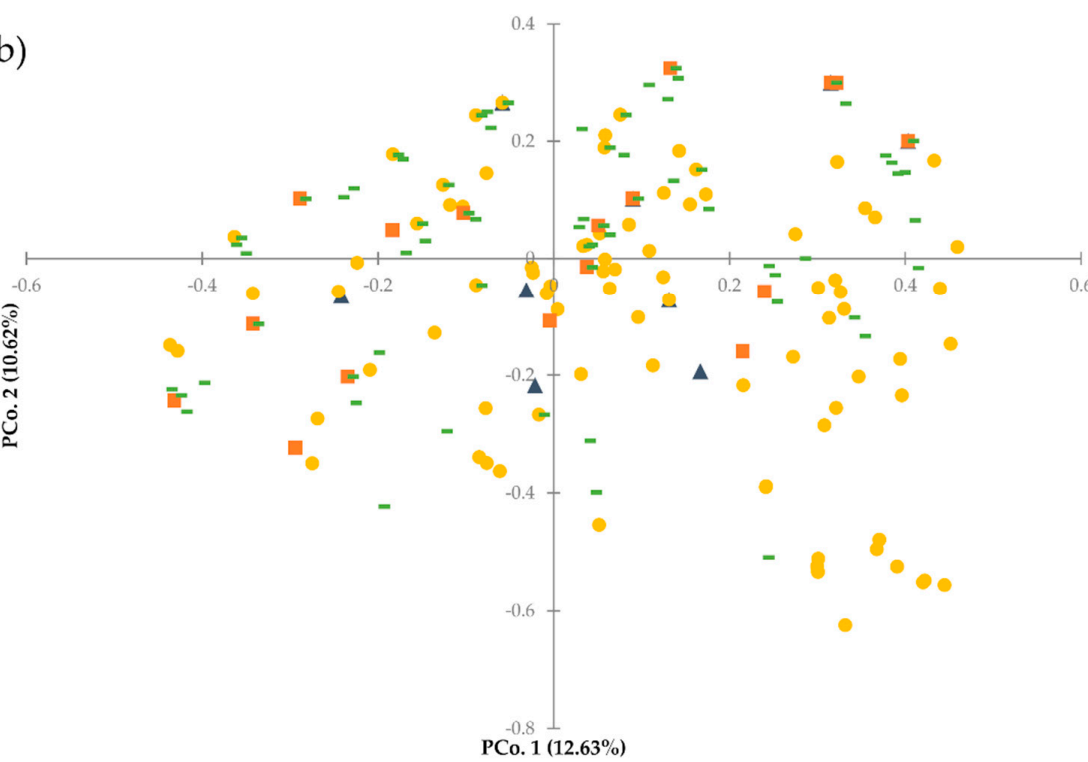

Figure 2. Analysis of principal coordinates (PCoA) with an accession origin marking; (a) for 41 accessions of Avena sterilis L. based on Nei's unbiased distance matrix [24]; (b) for 410 individuals of 41 accessions of $A$. sterilis based on Dice's dissimilarity matrix [23]. IRN = Iran, MAR = Morroco, $\mathrm{UKR}=$ Ukraine, $n a=$ not available 
(a)

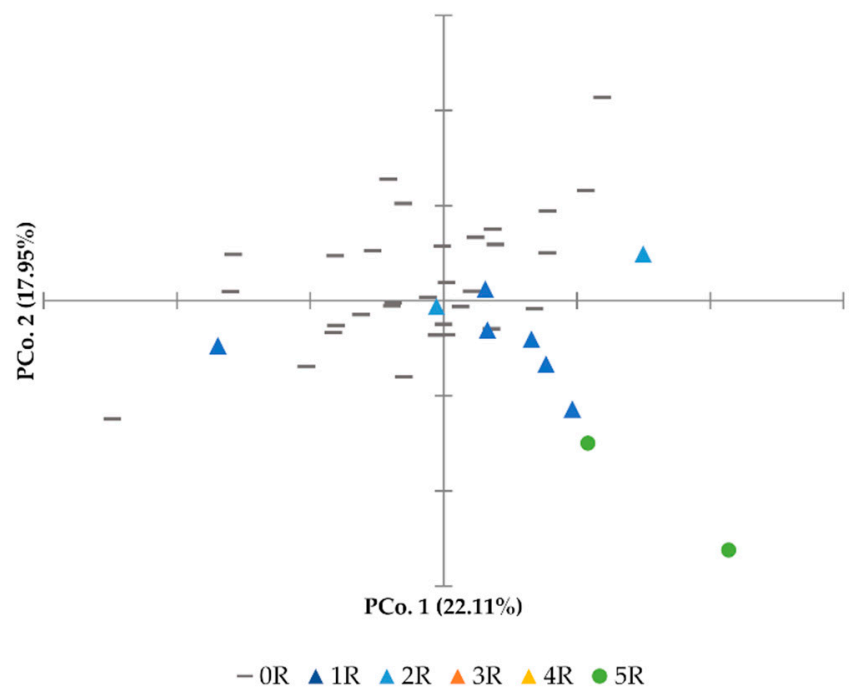

(b)

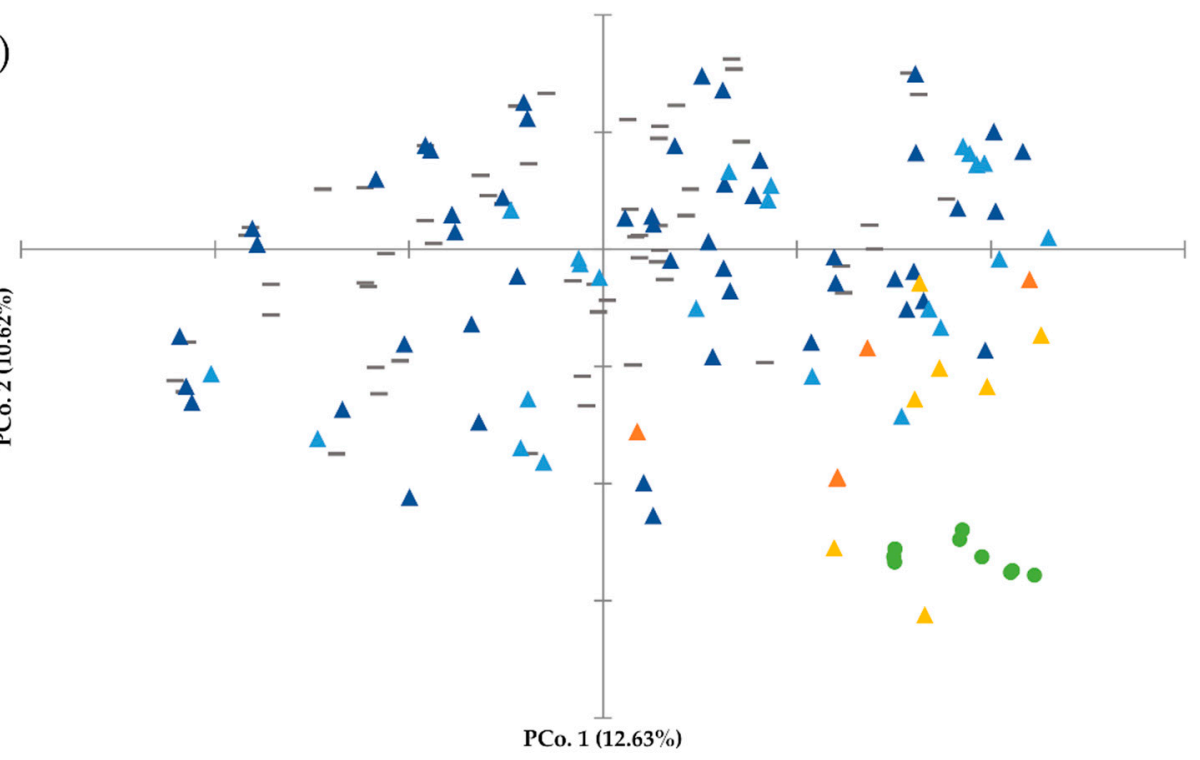

Figure 3. Analysis of principal coordinates ( $\mathrm{PCoA}$ ) with determination of resistance to tested isolates of Puccinia coronata f. sp. avenae, where $0 \mathrm{R}$ means susceptibility to all tested isolates, $1 \mathrm{R}-4 \mathrm{R}$ means resistance to 1-4 of the tested isolates, and $5 \mathrm{R}$ means resistance to all tested isolates; (a) for 41 accessions of Avena sterilis L. based on Nei's unbiased distance matrix [24]; (b) for 410 individuals of 41 accessions of $A$. sterilis based on Dice's dissimilarity matrix [23].

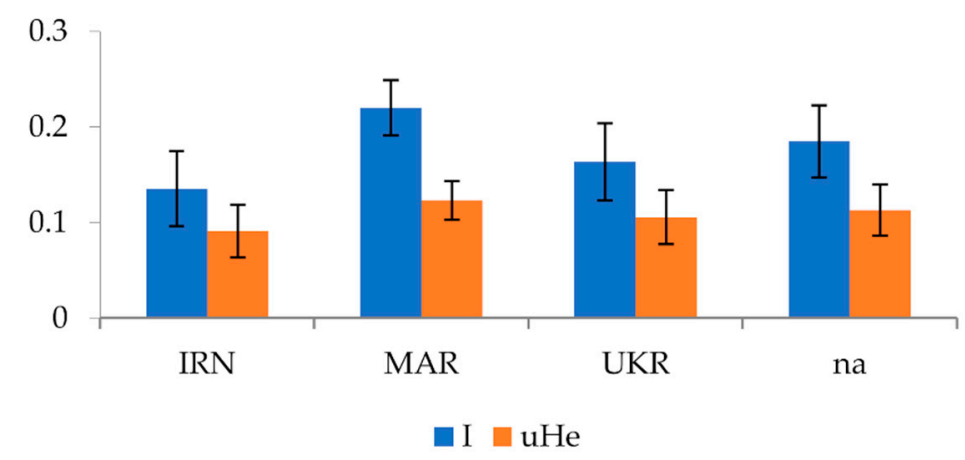

Figure 4. Levels of Shannon's index [21] and Nei's coefficient [22] indicating diversity for the groups determined by the collection site. 
(a)

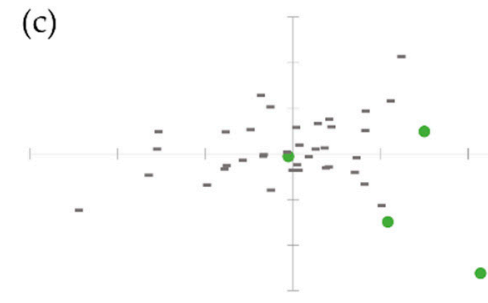

(e)

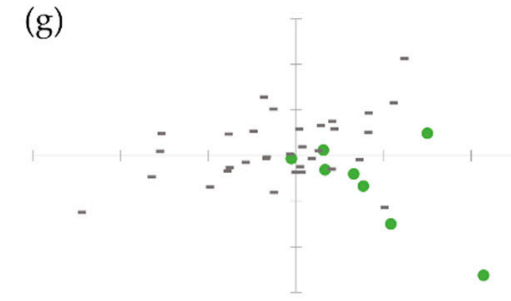

(i)

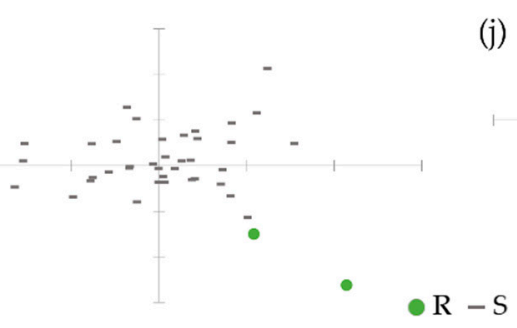

(b)

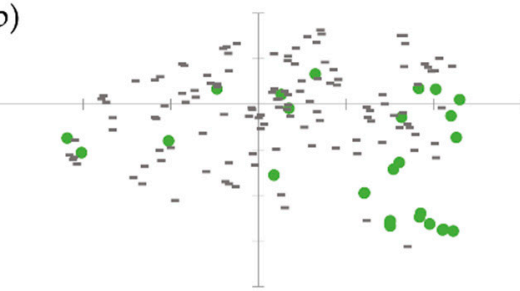

(d)

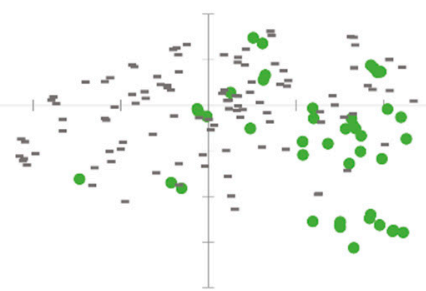

(f)

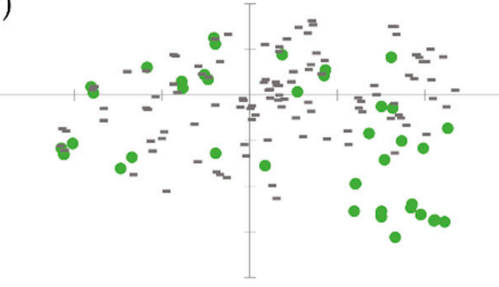

(h)

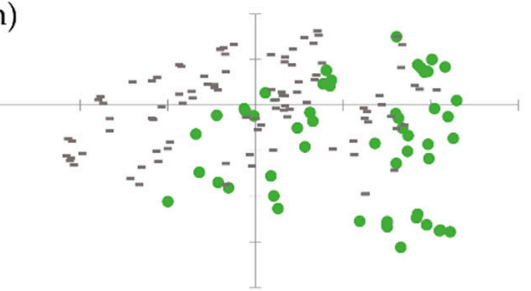

(j)

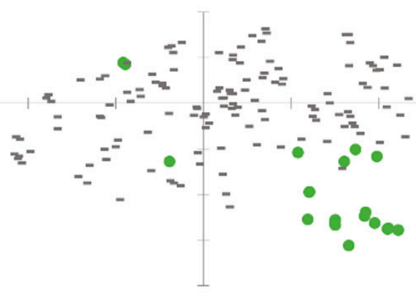

Figure 5. Plots of 1 vs 2 axis of principal coordinates analysis (PCoA) with the resistance $(\bigcirc R)$ and susceptibility (-S) of 41 accessions of Avena sterilis L. to specific isolates of Puccinia coronata f. sp. avenae (Pca) indicated; (a) generalized resistance of the accessions to the CR257 Pca isolate; (b) individuals' resistance to the CR257 Pca isolate; (c) generalized resistance of the accessions to the 51(22) Pca isolate; (d) individuals' resistance to the 51(22) Pca isolate; (e) generalized resistance of the accessions to the CR230 Pca isolate; (f) individuals' resistance to the CR230 Pca isolate; (g) generalized resistance of the accessions to the 94(63) Pca isolate; (h) individuals' resistance to the 94(63) Pca isolate; (i) generalized resistance of the accessions to the CR241 Pca isolate; (j) individuals' resistance to the CR241 Pca isolate.

Resistance to Pca isolate CR257 occurred in 46 individuals derived from 14 accessions (Figure 5b). Thirty-six individuals (eight accessions) came from Morocco, and the remainder came from six accessions of unknown origin. Only in one accession (PL 51836) were all individuals resistant to this isolate.

Seventy-four individuals from 16 accessions showed resistance to Pca isolate 51(22) (Figure $5 \mathrm{~d}$ ). A total of $63.5 \%$ of individuals (eight accessions) came from Morocco, 27\% (five accessions) from unknown locations, and the rest from Ukraine (three accessions). 
Among the Moroccan accessions, two (PL 51589 and PL 51836) demonstrated resistance of all individuals, while nine out of ten tested plants from the third (PL 51856) were resistant.

Seventy-one individuals were not susceptible to isolate CR230; they originated from a total of 17 accessions (Figure 5f). Forty-four plants were sourced from 10 accessions collected in Morocco, 1 was sourced from Ukraine, and the remaining 6 were sourced from accessions with an unknown collection site. All plants from three accessions (PL 51832, PL 51836, and PL 52209) were resistant to this Pca isolate.

Almost one in every four tested individuals showed resistance to isolate $94(63)$ (Figure 5h). Sixty-two plants came from ten Moroccan accessions, three came from one from Ukraine, and single plants came from each of the two Iranian accessions. The remaining 32 individuals came from 10 populations of unknown origin. All individuals in the three populations PL 51589, PL 51836, and PL 52110 were resistant. Ninety percent of plants of PL 51586 were also resistant.

Only 37 plants were characterized by resistance to isolate CR241 (Figure 5j). A total of $94.5 \%$ of these originated from seven Moroccan populations, and the remaining were from two accessions with unknown collection sites. Among them, in only one case (PL 51836) were all individuals resistant. Nine of the ten tested plants of PL 51856 also showed resistance.

The Bayesian model approach implemented in the STRUCTURE software was used for population structure analysis. The $\Delta \mathrm{K}$ peak was the highest for $\mathrm{K}=5$, supporting the presence of five distinct populations. Forty-one accessions were divided into five populations (Figure 6a) containing 12, 7, 9, 9, and 4 accessions. Further, on the basis of the membership fraction, accessions were categorized as pure (probability $\geq 0.8$ ) or admixed. P1 contained four pure accessions, or 76 (18.5\%) pure individuals (Figure 6b). In P2, no pure accession was included; however, as many as 64 (15.6\%) pure individuals were found in the whole set. P3 was composed of four pure accessions, or 64 (15.6\%) individuals. P4 contained three pure accessions, or 32 (7.8\%) individuals; and finally, in P5, two pure accessions were found, or $32(7.8 \%)$ individuals. The remaining 28 accessions and 171 individuals were classified as admixed. In general, P3 corresponded to susceptibility to all tested Pca strains, whereas P5 corresponded to the resistance to these isolates. P2 was associated with a decreased susceptibility to isolate 51(22). The higher the proportion of these groups in the accession, the higher the proportions of individuals with the above-described resistance pattern. For individuals, the contribution of P5 was reversely proportional to the number of isolates capable of infecting the particular plant, while P3 contribution was directly proportional to the susceptibility to the tested isolates. The other two populations, P2 and $\mathrm{P} 4$, indicated intermediate susceptibility values to the tested isolates. The analysis of the population structure in a graphical way refers to the results of the level of variation within the accession obtained with the use of the coefficient of Nei's diversity and Shannon's index. 
$(\mathrm{a})_{41}$

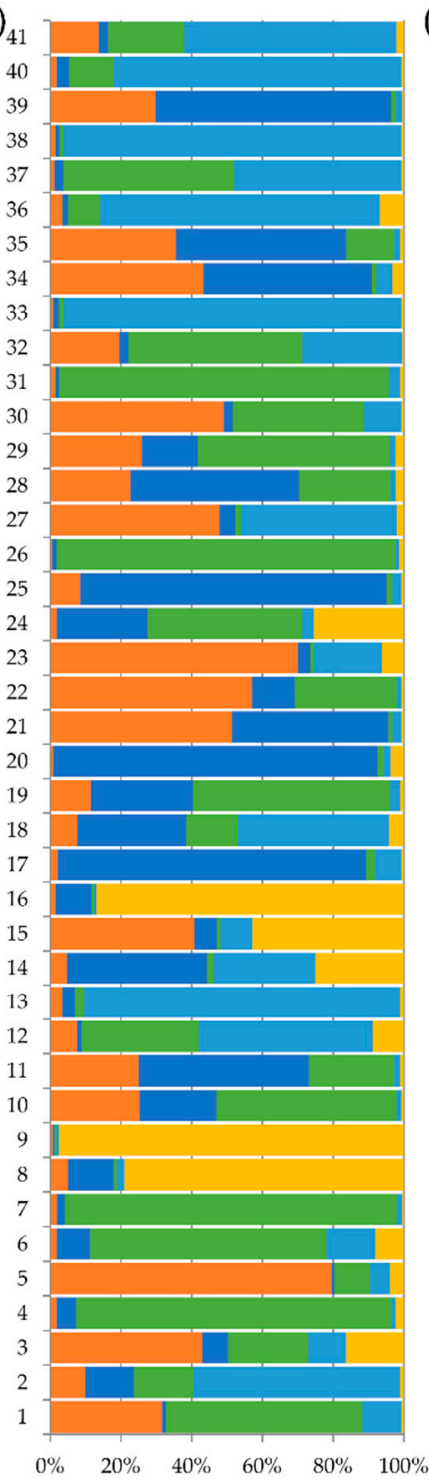

(b)

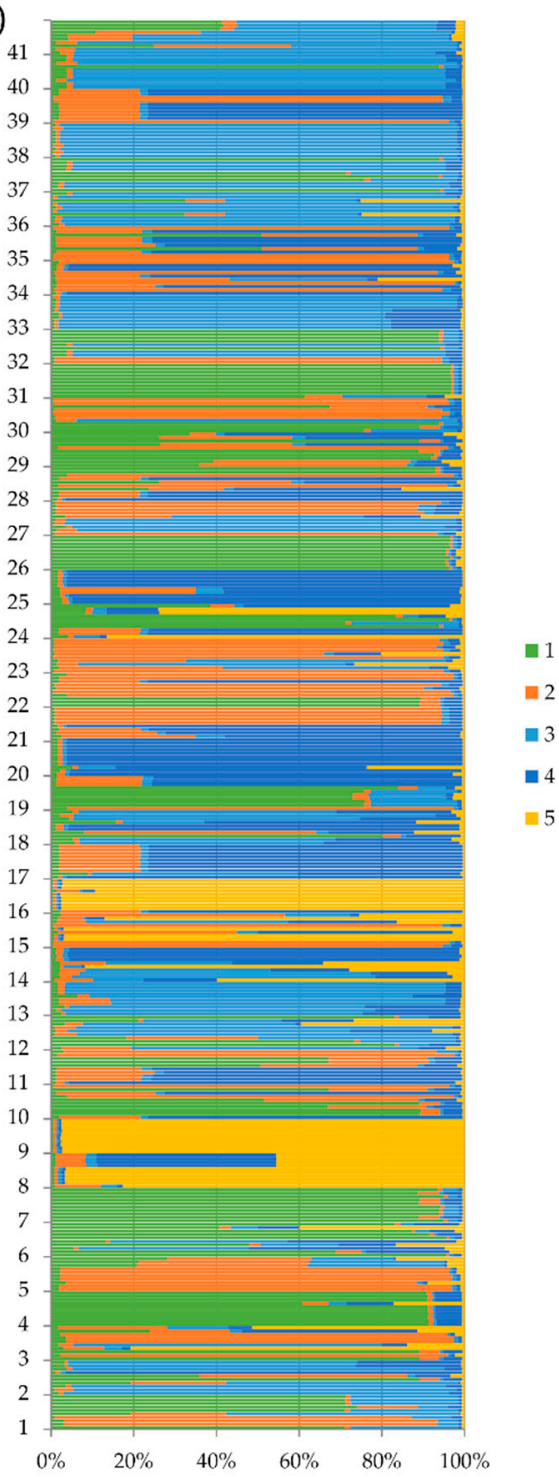

Figure 6. Bar graphs showing diversity structure of 41 accessions of Avena sterilis L. for resistance to five isolates of Puccinia coronata f. sp. avenae as assessed using STRUCTURE software [27]; (a) the graph for accessions; (b) the graph for 410 individuals. Each population is represented by a different colour.

\section{Discussion}

Currently oat breeding programmes, especially North American and Australian, are in urgent need of genetic sources from which new genes of $P$. coronata resistance can be introduced. The primary oat gene pool consists of hexaploid species that cross easily with cultivars and are widely used as donors of crown rust race-specific resistance genes. A. sterilis accessions collected in Israel and other Mediterranean countries in the 1960s and early 1970s were the main source of these genes [15,29].

The research presented here was carried out on 41 accessions from the Polish National Centre for Plant Genetic Resources, most of which were acquired during expeditions in Morocco, Ukraine, and Iran. Fifteen accessions of unconfirmed origin were also included. A set of highly virulent and diverse $P$. coronata isolates derived from populations collected in North America and Europe were used in this survey, enabling identification of potentially valuable resistance for use in current breeding programmes. Thirty-one (75\%) of the accessions studied showed a heterogeneous infection pattern, seven $(17 \%)$ were homogenously susceptible, and three $(7 \%)$ genotypes could be unambiguously described 
as resistant. Other studies on wild oat resistance have also revealed variable response to the rust inoculation within single accessions $[18,20,30]$. This study proved that $A$. sterilis accessions collected in Morocco, in particular, could be a very valuable source of resistance to crown rust. Among 17 investigated populations from this country, 11 displayed high seedling resistance to the $P$. coronata races used. This percentage of hexaploid species accessions with resistance to crown rust was higher than observed in other studies [30,31], but it was comparable to our previous results obtained in a survey of the tetraploids Avena magna Murphy et Terrell, Avena murphy Ladiz, and Avena insularis Ladiz [18]. The highest level of resistance in that study was also observed in accessions originating from Morocco. Saidi et al. [32] evaluated crown rust resistance in natural infection conditions of 288 accessions, which represented 13 species of wild oat gathered in Morocco. One hundred genotypes of $A$. sterilis were characterised, but only four were assessed as resistant or moderately resistant. Among the other analysed samples, 23 representing Avena longiglumis Durieu, Avena damascena Rajhathy et Baum, Avena wiestii Steud, Avena barbata Pott ex Link, and A. magna proved to be resistant. Tan and Carson [30] also analysed crown rust resistance of 332 accessions originating from Morocco and representing 11 wild oat species from the USDA-NSGC (United States Department of Agriculture National Small Grains Collection) in Aberdeen. Most of them were diploids and tetraploids, and only two accessions represented hexaploid $A$. sterilis. After screening this collection with a highly diverse population of $P$. coronata, about $50 \%$ of the accessions were recorded as at least moderately resistant at the seedling and adult plant stages. However, one $A$. sterilis accession was susceptible, and the other only moderately resistant. The results obtained by Saidi et al. [32] and Tan and Carson [30] favour the wild tetraploids and diploids from Morocco as the richest source of crown rust resistance.

Morocco is considered to be the centre of genus Avena origin, and out of all Avena species only three (Avena canariensis Baum, A. insularis, and Avena macrostachya Bal. ex Coss. et Dur) have not been recorded there [11,33]. Morocco's crop diversity results from longterm adaptation to various local environmental conditions such as drought, cold, and salinity $[34,35]$. Genetic variation at the genomic and population levels in both pathogens and their host plants are the effect of antagonistic interaction between them and their environment [36]. The fungus evolves parallelly and convergently to its hosts and results in the accumulation of many resistance and virulence genes [37]. Oates et al. [38] claim that in environments where pathogens are widespread and variable, heterogeneous resistance arises within populations.

A further complexity is the natural heterogeneity of accessions representing wild species gathered in genebanks $[18,30,39]$. Here, we have compared resistance within as well as between accessions. On the basis of the agglomerative hierarchical clustering and PCoA analysis, the distinctiveness among A. sterilis individuals and among accessions was demonstrated. Information based on the average of resistance across individuals from a given accession, which is standardly available in the gene bank databases, may obscure the presence of individuals with significant resistance to pathogens. The generalized information on the susceptibility of the entire accession makes researchers less interested in looking for new sources of resistance within it. As we have shown in this paper, at a time when available sources of oat resilience have failed, it is worth looking for desirable traits in accessions with general susceptibility, which have proven to be a hidden, valuable source of effective resistance.

\section{Conclusions}

Detailed variance analysis of transformed resistance/susceptibility data revealed hidden sources of resistance in A. sterilis accessions with general susceptibility. The study proved that accessions preserved in a genebank as complex populations could be a very valuable source of resistance to crown rust. 
Supplementary Materials: The following are available online at https:/ / www.mdpi.com/2073-439 5/11/2/315/s1, Figure S1: The Ward's clustering dendrogram of 410 individuals of 41 accessions of $A$. sterilis based on Dice dissimilarity matrix [23]. The accessions were labelled with numbers in accordance with Table S1. Individuals from each accession were additionally labelled with $a-j$ letters. Four main clusters were surrounded by contours and filled in, Table S1: Characteristics of $A$. sterilis accessions reactions to inoculation with $5 \mathrm{P}$. coronata isolates at the seedling stage. $\mathrm{S}=$ susceptible; $\mathrm{MS}=$ moderately susceptible; $\mathrm{MR}=$ moderately resistant; $\mathrm{R}$ = resistant; $\mathrm{HR}=$ highly resistant. Individuals from each accession were additionally labelled with a-j letters.

Author Contributions: Conceptualization and methodology, E.P.-G., M.B. and S.S.; investigation, J.T. and A.K.; resources, M.B.; writing-original draft preparation, E.P.-G. and M.B.; writing-review and editing, S.S.; visualization, M.B.; project administration, E.P.-G. All authors have read and agreed to the published version of the manuscript.

Funding: This research was supported by Ministry of Agriculture and Rural Development of the Republic of Poland Grant 2014-2020: "Crown rust resistance genes pyramiding in oat genome and identification of DNA markers for these genes". The calculations were made at the Interdisciplinary Centre for Mathematical and Computational Modelling of Warsaw University (ICM UW) as part of the computational grant no G72-19.

Institutional Review Board Statement: Not applicable.

Informed Consent Statement: Not applicable.

Data Availability Statement: Data sharing not applicable.

Conflicts of Interest: The authors declare no conflict of interest. The funders had no role in the design of the study; in the collection, analyses, or interpretation of data; in the writing of the manuscript, or in the decision to publish the results.

\section{References}

1. Carson, M.L. Crown Rust Development and Selection for Virulence in Puccinia coronata f. sp. avenae in an Oat Multiline Cultivar. Plant Dis. 2009, 93, 347-353. [CrossRef]

2. Carson, M.L. Virulence in Oat Crown Rust (Puccinia coronata f. sp. avenae) in the United States from 2006 through 2009. Plant Dis. 2011, 95, 1528-1534. [CrossRef] [PubMed]

3. Chong, J.; Gruenke, J.; Dueck, R.; Mayert, W.; Mitchell Fetch, J.W.; McCartney, C.A. Virulence of Puccinia coronata f. sp. avenae in the Eastern Prairie Region of Canada during 2007-2009. Can. J. Plant Pathol. 2011, 33, 77-87. [CrossRef]

4. Jiráková, H.; Hanzalová, A. Crown Rust Pathotypes Determined on Oats in the Czech Republic from 2004 to 2006 and Reaction to Oat Cultivars. Czech J. Genet. Plant Breed 2008, 2, 60-65. [CrossRef]

5. $\quad$ Menzies, J.G.; Xue, A.; Dueck, R.; Greunke, J. Virulence of Puccinia coronata f. sp. avenae in Canada; 2010 to 2014 . In Proceedings of the 14th International Cereal Rust and Powdery Mildew Conference, Copenhagen, Denmark, 5-8 July 2015 ; p. 95.

6. Simons, M.D. Crown rust. In The Cereal Rust Vol. 2 Diseases, Distribution, Epidemiology, and Control; Roelfs, A.P., Bushnel, W.R., Eds.; Academic Press: Orlando, FL, USA, 1985; pp. 131-172.

7. Gnanesh, B.N.; Fetch, J.M.; Zegeye, T.; McCartney, C.A.; Fetch, T. Oat. In Alien Gene Transfer in Crop Plants; Pratap, A., Kumar, J., Eds.; Springer: New York, NY, USA; Heidelberg, Germany; Dordrecht, The Netherlands; London, UK, 2014; Volume 2, pp. 51-73. ISBN 978-1-4614-8584-1.

8. Gnanesh, B.N.; Mitchell Fetch, J.W.; Menzies, J.G.; Beattie, A.D.; Eckstein, P.E.; McCartney, C.A. Chromosome Location and Allele-Specific PCR Markers for Marker-Assisted Selection of the Oat Crown Rust Resistance Gene Pc91. Mol. Breed. 2013, 32, 679-686. [CrossRef]

9. Loskutov, I.G.; Rines, H.W. Avena. In Wild Crop Relatives: Genomic and Breeding Resources; Kole, C., Ed.; Springer: Berlin/Heidelberg, Germany, 2011; pp. 109-183. ISBN 978-3-642-14227-7.

10. Nazareno, E.S.; Li, F.; Smith, M.; Park, R.F.; Kianian, S.F.; Figueroa, M. Puccinia coronata f. sp. avenae: A Threat to Global Oat Production. Mol. Plant Pathol. 2018, 19, 1047-1060. [CrossRef]

11. Boczkowska, M.; Podyma, W.; Łapiński, B. Oat. In Genetic and Genomic Resources for Grain Cereals Improvement; Singh, M., Upadhyaya, H.D., Eds.; Elsevier: Amsterdam, The Netherlands, 2016; pp. 159-225. ISBN 9780128020005.

12. Cabral, A.L.; Park, R.F. Seedling Resistance to Puccinia coronata f. sp. avenae in Avena Strigosa, A. Barbata and A. Sativa. Euphytica 2014, 196, 385-395. [CrossRef]

13. CDL Cereal Disease Laboratory. Resist. Genes. Available online: https//www.ars.usda.gov/midwest-area/stpaul/cerealdisease-lab/docs/resistance-genes/resistance-genes / (accessed on 4 October 2018). 
14. Šebesta, J.; Zwatz, B.; Roderick, H.; Corazza, L.; Manisterski, J.; Stojanovic, S. Incidence of Crown Rust and Virulence of Puccinia coronata Cda. f. sp. avenae Eriks. and the Effectiveness of $P_{c}$ Genes for Resistance in Europe, Middle East and North Africa. Arch. Phytopathol. Plant Prot. 2003, 36, 179-194. [CrossRef]

15. Simons, M.D.; Martens, J.W.; McKenzie, R.I.H.; Nishiyama, I.; Sadanaga, K.; Šebesta, J.; Thomas, H. Oats: A Standardized System of Nomenclature for Genes and Chromosomes and Catalog of Genes Governing Characters; US Department of Agricultural Handbook No. 509; US Department of Agriculture: Madison, WI, USA, 1978.

16. Paczos-Grzęda, E.; Sowa, S.; Boczkowska, M.; Langdon, T. Detached Leaf Assays for Resistance to Crown Rust Reveal Diversity within Populations of Avena Sterilis L. Plant Dis. 2018. [CrossRef]

17. Hsam, S.L.K.; Peters, N.; Paderina, E.V.; Felsenstein, F.; Oppitz, K.; Zeller, F.J. Genetic Studies of Powdery Mildew Resistance in Common Oat (Avena sativa L.) I. Cultivars and Breeding Lines Grown in Western Europe and North America. Euphytica 1997, 96, 421-427. [CrossRef]

18. Sowa, S.; Paczos-Grzęda, E.; Koroluk, A.; Okoń, S.; Ostrowska, A.; Ociepa, T.; Chrząstek, M.; Kowalczyk, K. Resistance to Puccinia coronata f. sp. avenae in Avena magna, A. murphyi, and A. insularis. Plant Dis. 2016, 100, 1184-1191. [CrossRef]

19. Murphy, H.C. Physiologic Specialisation in Puccinia coronata f. sp. avenae. Bull. U.S. Dep. Agric. 1935, $433,1-48$.

20. Carson, M.L. Broad-Spectrum Resistance to Crown Rust, Puccinia coronata f. sp. avenae, in Accessions of the Tetraploid Slender Oat, Avena barbata. Plant Dis. 2009, 93, 363-366. [CrossRef] [PubMed]

21. Brown, A.H.; Weir, B.S. Measuring Genetic Variability in Plant Populations. Isozymes Plant Genet. Breed. 1983, 1, $219-239$.

22. Hartl, D.L.; Clark, A.G. Principles of Population Genetics; Hedrick, P., Ed.; Jones \& Bartlett Learning: Tempe, AZ, USA, 1998.

23. Dice, L.R. Measures of the Amount of Ecologic Association between Species. Ecology 1945, 26, 297-302. [CrossRef]

24. Hedrick, P. Genetics of Populations; Jones \& Bartlett Learning: Tempe, AZ, USA, 2011.

25. Excoffier, L.; Smouse, P.E.; Quattro, J.M. Analysis of Molecular Variance Inferred from Metric Distances among DNA Haplotypes: Application to Human Mitochondrial DNA Restriction Data. Genetics 1992, 131, 479-491. [CrossRef]

26. Peakall, R.; Smouse, P.E. Genalex 6: Genetic Analysis in Excel. Population Genetic Software for Teaching and Research. Mol. Ecol. Notes 2006, 6, 288-295. [CrossRef]

27. Hubisz, M.J.; Falush, D.; Stephens, M.; Pritchard, J.K. Inferring Weak Population Structure with the Assistance of Sample Group Information. Mol. Ecol. Resour. 2009, 9, 1322-1332. [CrossRef] [PubMed]

28. Kopelman, N.M.; Mayzel, J.; Jakobsson, M.; Rosenberg, N.A.; Mayrose, I. Clumpak: A Program for Identifying Clustering Modes and Packaging Population Structure Inferences across K. Mol. Ecol. Resour. 2015, 15, 1179-1191. [CrossRef]

29. Leonard, K.J.; Anikster, Y.; Manisterski, J. Patterns of Virulence in Natural Populations of Puccinia coronata on Wild Oat in Israel and in Agricultural Populations on Cultivated Oat in the United States. Phytopathology 2004, 94, 505-514. [CrossRef]

30. Tan, M.Y.A.; Carson, M.L. Screening Wild Oat Accessions from Morocco for Resistance to Puccinia coronata. Plant Dis. 2013, 97, 1544-1548. [CrossRef] [PubMed]

31. Saidi, N.; Ladizinsky, G. Distribution and Ecology of the Wild Tetraploid Oat Species Avena Magna and A. Murphyi in Morocco. In Proceedings of the Report of a Cereals Network 1st Meeting, Yerevan, Armenia, 3-5 July 2003; IPGRI: Rome, Italy, 2005; pp. 70-73.

32. Saidi, S.; Ez zahiri, B.; Lepoivre, P. Virulence Analysis of Crown Rust (Puccinia coronata f. sp. avenae) of Oats in Morocco. AL AWAMIA 114 2005, 2, 3-20.

33. Leggett, J.M. Classification and Speciation in Avena. In Oat Science and Technology; Marshall, H.G., Sorrells, M.E., Eds.; Agronomy Monograph; American Society of Agronomy, Crop Science Society of America: Madison, WI, USA, 1992; pp. 29-52. ISBN 978-0-89118-225-2.

34. Graves, W. Moroccan Indigenous Plants Collection Program. In TDY Report; Utah State University, Range Improvement Project; Utah State University, USU Press: Rabat, Morocco, 1985; p. 337.

35. Sauvage, C. L'état actuel de nos connaissances sur la lore du Maroc. In La Lore du Bassin Méditerranéen. Essai de Systématique Synthétique; CNRS: Paris, France, 1975; pp. 131-142.

36. Van der Hoorn, R.A.; De Wit, P.J.; Joosten, M.H. Balancing Selection Favors Guarding Resistance Proteins. Trends Plant Sci. 2002, 7, 67-71. [CrossRef]

37. Flor, H.H. Current Status of the Gene-for-Gene Concept. Annu. Rev. Phytopathol. 1971, 9, 275-296. [CrossRef]

38. Oates, J.D.; Burdon, J.J.; Brouwer, J.B. Interactions between Avena and Puccinia Species. II. The Pathogens: Puccinia coronata Cda and P. graminis Pers. f. sp. avenae Eriks. \& Henn. J. Appl. Ecol. 1983, 20, 585-596.

39. Gregová, E.; Hermuth, J.Í.; Kraic, J.; Dotlail, L. Protein Heterogeneity in European Wheat Landraces and Obsolete Cultivars. Genet. Resour. Crop Evol. 1999, 46, 521-528. [CrossRef] 